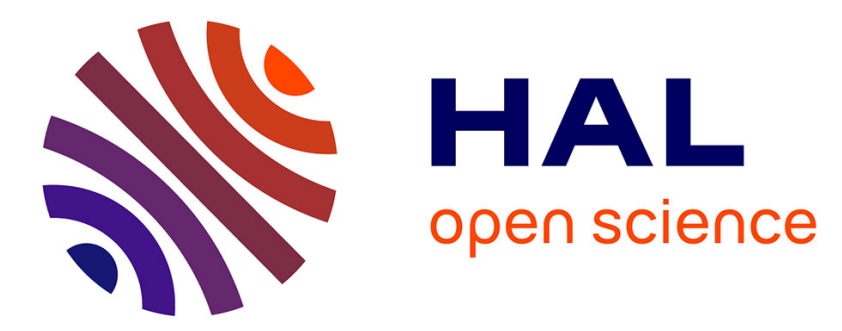

\title{
Low cycle fatigue behaviour of $\beta$ treated zirconium: partial irreversibility of twinning and consequences for damage
}

Jérôme Crépin, Thierry Bretheau, Daniel Caldemaison, Franck Ferrer

\section{- To cite this version:}

Jérôme Crépin, Thierry Bretheau, Daniel Caldemaison, Franck Ferrer. Low cycle fatigue behaviour of $\beta$ treated zirconium: partial irreversibility of twinning and consequences for damage. Acta Materialia, 2000, 48, pp.505-516. 10.1016/S1359-6454(99)00358-4 . hal-00111288

\author{
HAL Id: hal-00111288 \\ https://hal.science/hal-00111288
}

Submitted on 19 Mar 2021

HAL is a multi-disciplinary open access archive for the deposit and dissemination of scientific research documents, whether they are published or not. The documents may come from teaching and research institutions in France or abroad, or from public or private research centers.
L'archive ouverte pluridisciplinaire HAL, est destinée au dépôt et à la diffusion de documents scientifiques de niveau recherche, publiés ou non, émanant des établissements d'enseignement et de recherche français ou étrangers, des laboratoires publics ou privés.

\section{(c)(1)}

Distributed under a Creative Commons Attribution| 4.0 International License 


\title{
LOW CYCLE FATIGUE BEHAVIOUR OF $\beta$ TREATED ZIRCONIUM: PARTIAL IRREVERSIBILITY OF TWINNING AND CONSEQUENCES FOR DAMAGE
}

\author{
J. CRÉPIN $\dagger$, T. BRETHEAU, D. CALDEMAISON and F. FERRER \\ Laboratoire de Mécanique des Solides, C.N.R.S. UMR 7649, École Polytechnique, 91128 Palaiseau
}

Cedex, France

\begin{abstract}
The aim of this study is to understand the low cycle fatigue behaviour of $\beta$ treated zirconium. It focuses especially on the contribution of twinning mechanisms. In situ fatigue tests performed inside a scanning electron microscope allow the observation of the activation of twins and their partial reversibility, depending on the applied stress. Moreover, the acoustic signature (shape factor) of the different twinning systems has been characterized allowing the following of inception and evolution of twins during the fatigue tests. Finally, the consequence of such a partial irreversibility on damage and crack localization is shown.

Résumé - Cette étude a pour but la compréhension du comportement en fatigue oligocyclique du zirconium traité $\beta$ et elle se focalise tout particulièrement sur la contribution du maclage. Des essais de fatigue in situ réalisés dans un microscope électronique à balayage ont permis d'observer l'activation des mécanismes de maclage ainsi que leur réversibilité partielle en relation avec la contrainte appliquée. De plus, la signature acoustique (facteur de forme) des différents systèmes de maclage a été caractérisée ce qui a permis de suivre l'apparition et l'évolution des macles au cours des essais de fatigue. Enfin la conséquence d'une telle irréversibilité partielle sur la localisation de l'endommagement et de la fissuration est établie.
\end{abstract}

Keywords: Low cycle fatigue; Scanning electron microscopy (SEM); Alloys (zirconium); Mechanical properties (fatigue); Microstructure

\section{INTRODUCTION}

Zirconium is mainly used in the nuclear industry as a structural material. It is therefore necessary to guarantee the integrity and safety of the structures composed of this material under service conditions. For that purpose, the improvement and optimization of the mechanical behaviour of zirconium is required, especially in the field of the fatigue of welded joints. In this research direction, our interest has focused on the reversibility of twinning mechanisms linked with prescribed cyclic strain at room temperature and on the consequences for damage and rupture. This study is based on the study of twinning mechanisms at different scales (from macroscopic to scanning electron microscopySEM - scales) in relation with the overall mechanical response. Specifically, macroscopic tension/compression fatigue tests were performed while recording acoustic emissions to detect the inception of twinning, and in situ fatigue tests were performed

$\dagger$ To whom all correspondence should be addressed. inside the SEM chamber to observe the evolution of twins.

The paper is arranged as follows: Section 2 consists of a brief description of the studied material's microstructure and of its deformation mechanisms; Section 3 concerns the experimental techniques used. The experimental results are then presented in Section 4 followed by a closing discussion in Section 5 .

\section{MATERIAL}

Grade 702 zirconium contains $0.5 \%$ (in weight) foreign elements listed in Table 1. This material has undergone an $\alpha \rightarrow \beta \rightarrow \alpha$ cycle at a slow cooling rate $\left(\approx 15^{\circ} / \mathrm{s}\right)$ inducing a bainitic transformation from the high temperature $\beta$ phase (body centred cubic) to the low temperature $\alpha$ phase (hexagonal close packed). The resulting Widmanstätten microstructure, presented in Fig. 1, consists of colonies $(\approx 500 \mu \mathrm{m}$ grain size $)$ of parallel laths with the same crystallographic orientation. The lath boundaries are "walls" constituted of precipitates of betagenic 
Table 1. Chemical composition of grade 702 zirconium

\begin{tabular}{lcccccccc}
\hline Elements & $\mathrm{C}$ & $\mathrm{H}$ & $\mathrm{O}$ & $\mathrm{N}$ & $\mathrm{Cr}$ & $\mathrm{Fe}$ & $\mathrm{Ni}$ & $\mathrm{Sn}$ \\
\hline Analysis (wt p.p.m.) & 58 & $4-7$ & 1400 & 33 & 240 & 760 & 50 & 2280 \\
\hline
\end{tabular}

elements (Fe, $\mathrm{Cr}, \mathrm{Ni})$ [1]. The alphagenic elements such as $\mathrm{Sn}$ and $\mathrm{O}$ remain in the solid solution $(\alpha$ phase) [2].

The texture is assumed to be isotropic because of the $\beta$ treatment undergone by the material.

Three major deformation mechanisms are activated under tensile conditions at room temperature: $(10 \overline{1} 0)\langle 1 \overline{2} 10\rangle$ prismatic slip, $(10 \overline{1} 2)\langle 10 \overline{1} \overline{1}\rangle$ and $(11 \overline{2} 1)\langle 11 \overline{2} \overline{6}\rangle$ twinning depending on the colony crystallographic orientation with respect to the tensile axis. Prismatic slip is either homogeneous or concentrated in coarse slip lines along the lath boundaries [2]. This last mechanism is most frequently observed.

\section{EXPERIMENTAL TECHNIQUES}

The samples are cut along the former rolling direction, and their dimensions for macroscopic and "in situ" fatigue tests are: $8 \mathrm{~mm}$ diameter, $20 \mathrm{~mm}$ gauge length and $4.5 \mathrm{~mm}$ diameter, $8 \mathrm{~mm}$ gauge length, respectively. Low cycle fatigue tests under total strain control are performed at room temperature and at a constant nominal strain rate of $10^{-3} / \mathrm{s}$ in symmetrical conditions $\left(R_{\varepsilon}=\varepsilon_{\min } / \varepsilon_{\max }=-1\right)$; the total strain amplitude ranges between 0.20 and $0.80 \%$. The different tests start either in tension (type A) (Fig. 2) or in compression (type B). In the following, the first half of the cycle is called "part 1 " and the second "part 2". The different variables $x(\sigma, \varepsilon, \ldots)$ associated with part 1 and part 2 are defined as $x_{\text {part } 1}, x_{\text {part2 }}$, respectively.

To locate, identify and follow the occurrence and evolution of the various deformation mechanisms, a Raith tension/compression loading stage located inside the scanning electron microscope is used with a $5 \times 10^{-4} / \mathrm{s}$ strain rate [3] under stress control conditions. These tests start in tension for a ratio $R_{\sigma}=$ $\sigma_{\min } / \sigma_{\max }=-1$ and are performed at room temperature under vacuum $\left(\approx 10^{-4} \mathrm{~Pa}\right)$.

All the samples are mechanically and electrolytically polished [1]. Gold microgrids $\left(1 \mathrm{~mm}^{2}\right)$ with $5 \mu \mathrm{m}$ pitch deposited on the sample surface give access to qualitative and quantitative characteriz-

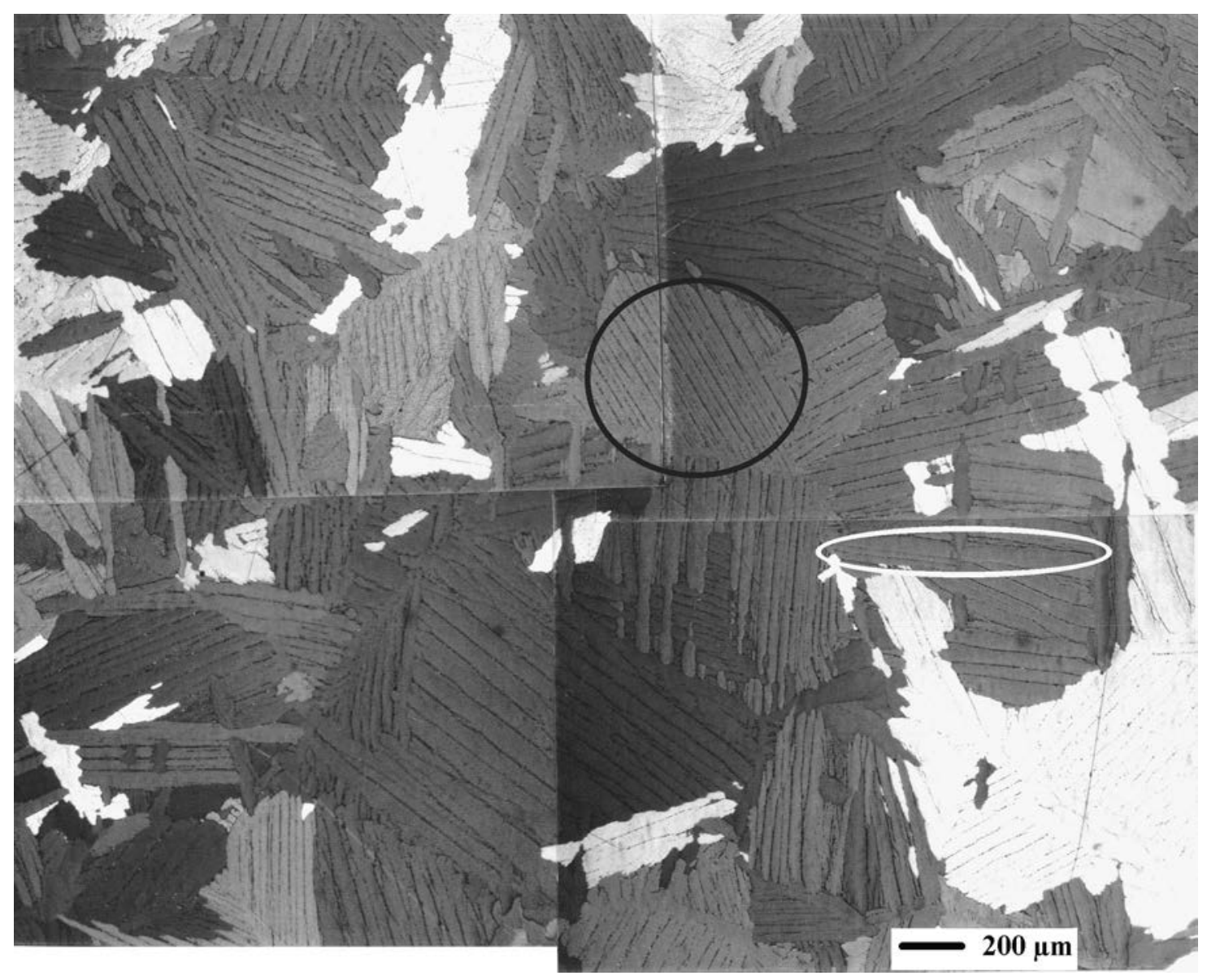

Fig. 1. Microstructure of $\beta$ treated 702 zirconium after electrolytic polishing (polarized light microscopy). The white ellipse delimits a lath and the black one delimits a colony. 


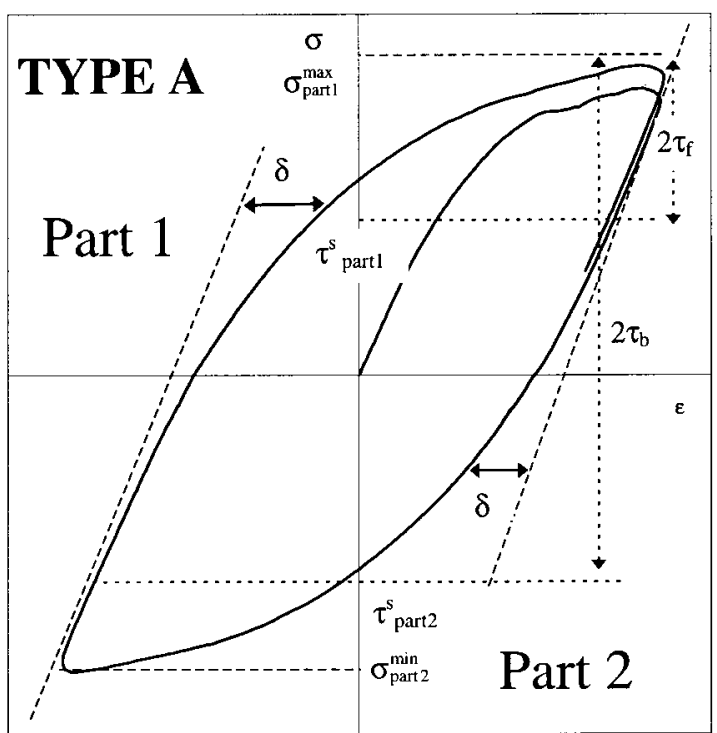

Fig. 2. Fatigue test parameters (type A test). $\delta$ is a parameter characteristic of the deviation from linearity of the unloading curve; it allows an unambiguous value for the yield stress $\tau^{\mathrm{s}}$ to be given. The frictional stress $\tau_{\mathrm{f}}$ and the back stress $\tau_{\mathrm{b}}$ are derived from $\tau^{\mathrm{s}}$ [8]. For type B test, parts 1 and 2 are reversed.

ation of the local deformation mechanisms [4]. The local crystallographic orientation of $1 \mu \mathrm{m}^{3}$ crystal domains is determined by electron backscattering diffraction (EBSD). This technique makes it possible to identify the effective active slip and twinning systems as well as to estimate their Schmid factor.

A twin formation mechanism corresponds to an instantaneous reorientation of a certain crystal volume by homogeneous shear; the potential twins in zirconium are listed in Table 2. The shear amplitude is determined by the crystallographic relationship between the two undistorted planes $\left(K_{1}\right.$ and $K_{2}$ ) and takes different values for different twinning systems. The acoustic signal produced by a twin is related to the shear amplitude permitting the classification of the twinning mechanisms. As mentioned in Ref. [5], different global variables can characterize an acoustic emission such as the maximum amplitude $\left(V_{\mathrm{c}}\right)$, the average amplitude value $\left(V_{\mathrm{m}}\right)$, the efficiency value or r.m.s. value $\left(V_{\text {r.m.s. }}\right)$ or the energy $(E)$. The definitions of these variables are as follows:

$$
V_{\mathrm{m}}(t)=\frac{1}{T} \int_{t}^{t+T} V(\tau) \mathrm{d} \tau \quad \text { with } T=1-10 \mathrm{~ms}
$$

$$
V_{\mathrm{ms}}(t)=\sqrt{\frac{1}{T} \int_{t}^{t+T}[V(\tau)]^{2} \mathrm{~d} \tau}
$$

with $T=10 \mathrm{~ms}$ to a few seconds

$$
E(t)=\int_{0}^{t} V^{2}(\tau) \mathrm{d} \tau .
$$

The emission shape factor $\Delta V_{\mathrm{c}} / \Delta V_{\text {r.m.s. }}$, defined by the ratio of the maximum amplitude to the efficiency value of the signal is a pertinent signature of a twinning system. Detection is performed with a piezo-electric sensor with a $20 \mathrm{kHz}$ filter and a sampling period of $100 \mathrm{~ns}$ during type A and B tests on an Instron machine at a nominal $10^{-4} / \mathrm{s}$ strain rate.

\section{RESULTS}

\subsection{Macroscopic characterization}

Most of the fatigue tests start in tension (type A) (Fig. 2). The evolution with strain of the macroscopic and microscopic characteristics [isotropic hardening $(R)$ and kinematical hardening $(X)$, friction stress $\left(\tau_{\mathrm{f}}\right)$ and back stress $\left.\left(\tau_{\mathrm{b}}\right)\right]$ is determined in accordance with the methods of Cottrell [7], Kuhlmann-Wilsdorf and Laird [8] and Lemaitre and Chaboche [9]. The definitions of the different variables introduced above, based on Ref. [8] and for symmetrical loading conditions are:

$$
\begin{aligned}
\tau_{\mathrm{f}} & =\left(\tau_{\max }+\tau^{\mathrm{s}}\right) / 2 \\
\tau_{\mathrm{b}} & =\left(\tau_{\max }-\tau^{\mathrm{s}}\right) / 2
\end{aligned}
$$

with $\tau^{\mathrm{s}}=\left(\tau_{\text {part1 }}^{\mathrm{s}}-\tau_{\text {part } 2}^{\mathrm{s}}\right) / 2$ and $\tau_{\max }=\left(\sigma_{\max }-\sigma_{\min }\right) / 2$

$$
X=\tau_{\mathrm{b}}
$$

$$
R=\tau_{\mathrm{f}}-k \quad \text { with } k \text { the initial yield stress. }
$$

Note that $\tau_{\text {part1 }}^{\mathrm{s}}$ and $\tau_{\text {part2 }}^{\mathrm{s}}$ are determined on the basis of a deviation from linearity with a coefficient $\delta=10^{-4}$ (Fig. 2).

It appears that hardening is mainly kinematical,

\begin{tabular}{|c|c|c|c|c|}
\hline First undistorted plane, $K_{1}$ & Twinning shear direction, $\eta_{1}$ & Second undistorted plane, $K_{2}$ & $\eta_{2}$ & Shear magnitude \\
\hline$\{10 \overline{1} 2\}$ & $\langle 10 \overline{1} \overline{1}\rangle$ & $\{10 \overline{1} \overline{2}\}$ & $\langle 10 \overline{1} 1\rangle$ & 0.167 \\
\hline$\{11 \overline{2} 1\}$ & $\langle 11 \overline{2} \overline{6}\rangle$ & $\{0002\}$ & $\langle 11 \overline{2} 0\rangle$ & 0.63 \\
\hline$\{11 \overline{2} 2\}$ & $\langle 11 \overline{2} \overline{3}\rangle$ & $\{11 \overline{2} \overline{4}\}$ & $\langle 22 \overline{4} 3\rangle$ & 0.225 \\
\hline
\end{tabular}
since the isotropic contribution is negligible (Fig. 3). This hardening remains constant with the number of cycles $(N)$ for a given strain amplitude $(\Delta \varepsilon / 2)$, but increases with amplitude. By contrast, it is found that friction stress $\tau_{\mathrm{f}}$ remains stable with $N$

Table 2. Twinning elements in pure zirconium [6] 


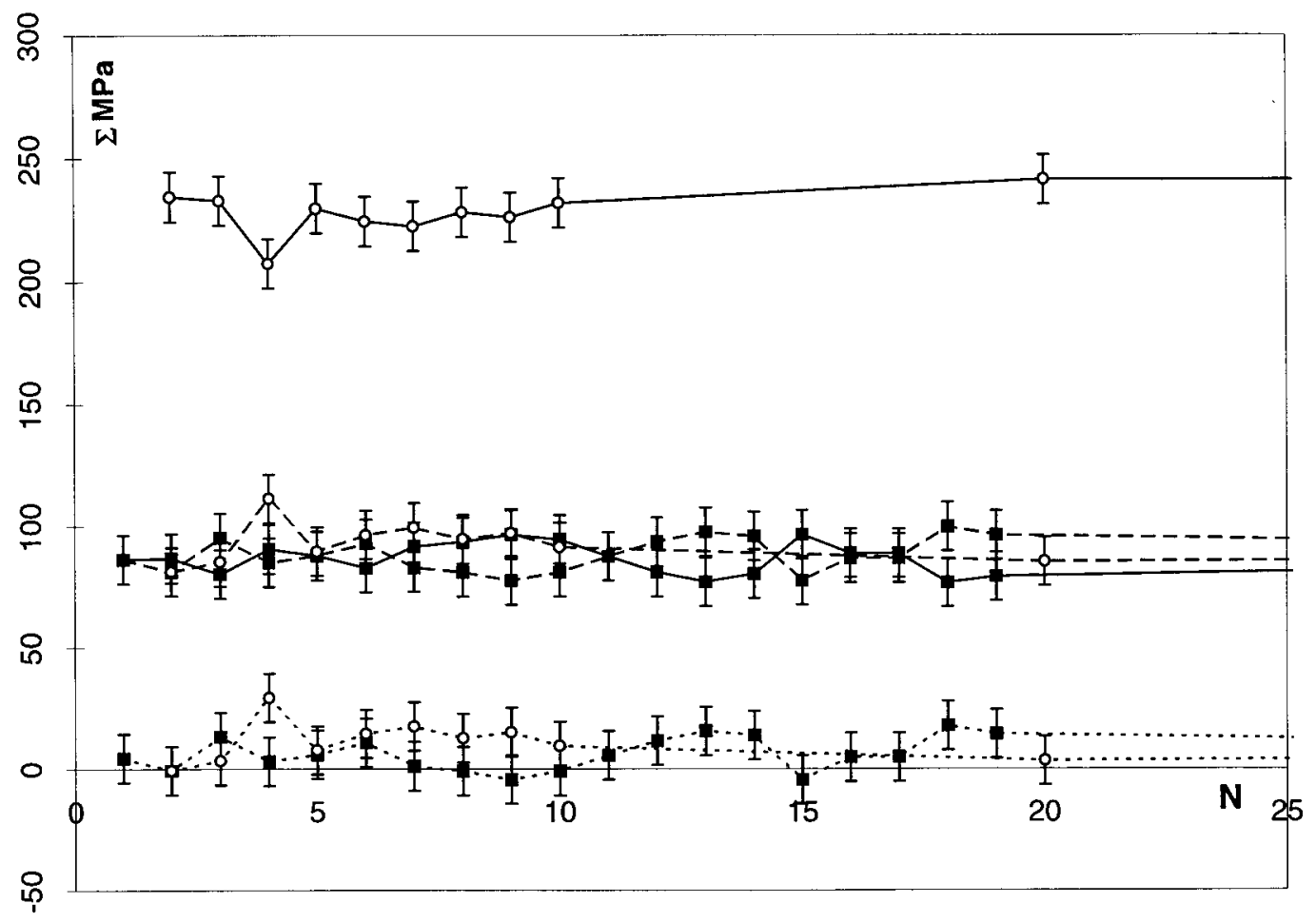

Fig. 3. Evolution of the isotropic hardening, kinematical hardening, back stress and the friction stress vs $N$ for different total strain amplitudes: $\square, \Delta \varepsilon / 2=0.20 \% ; \bigcirc, \Delta \varepsilon / 2=0.80 \%$. - , kinematical hardening (back stress $\tau_{\mathrm{b}}$ ); ---, friction stress $\tau_{\mathrm{f}} ;-_{--}-$- , isotropic hardening.

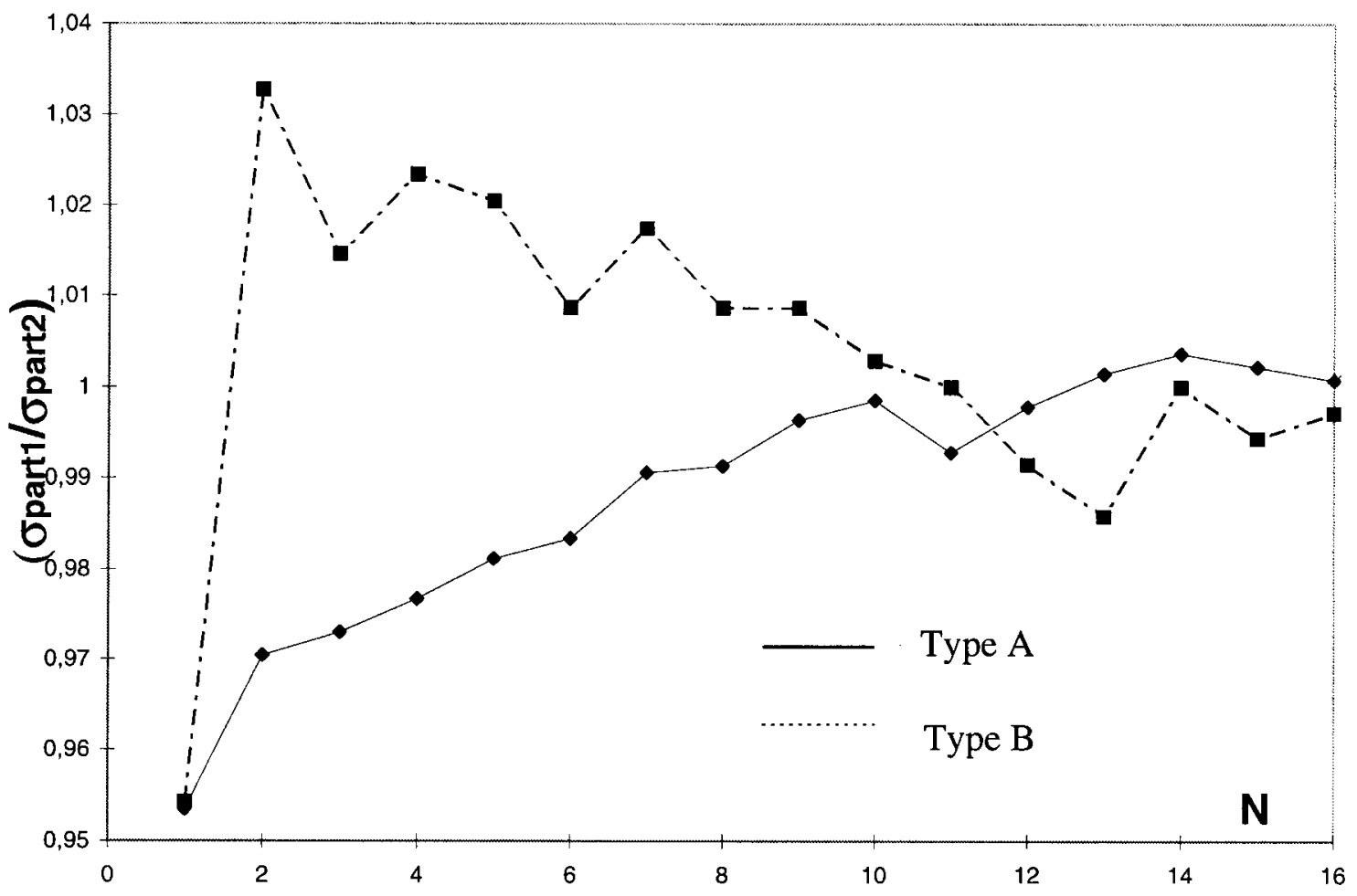

Fig. 4. Comparison of the stress response symmetry. Total strain amplitude $\Delta \varepsilon / 2=0.80 \%$. 


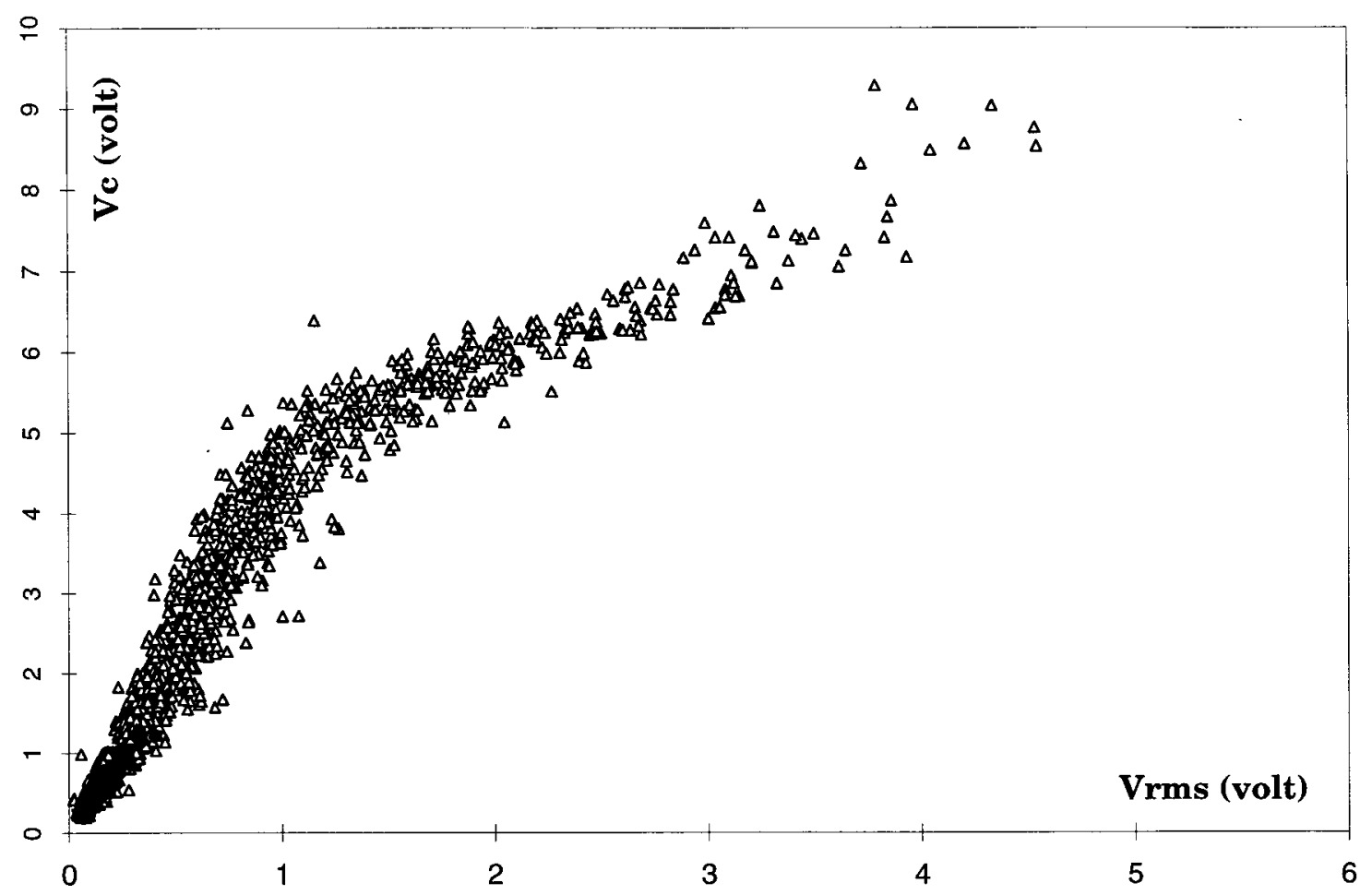

Fig. 5. Amplitude $\left(V_{\mathrm{c}}\right)$ vs the efficiency value $\left(V_{\text {r.m.s. }}\right)$ of the acoustic emission during monotonic tensile tests: $\square$, grade $702 \alpha$ zirconium with small grain size [9]; $\triangle, \beta$ treated grade $702 \alpha$ zirconium [2].

and is independent of the strain amplitude. Moreover, Fig. 4 allows the symmetry of the stress response for a symmetric applied strain to be checked $(\Delta \varepsilon / 2=0.8 \%)$. The first cycle shows, either for type A or B test, that $\sigma_{\text {part2 }}$ is always higher than $\sigma_{\text {part1 }}$ with a stress ratio of 0.95 ; this ratio increases for type A tests but, after a maximum for the second cycle, decreases for type $\mathrm{B}$ tests. The cycles tend to symmetrize (ratio of 1) after the first 10 cycles. This means that besides the first cycle the stress response of the material is exactly the same for type $\mathrm{A}$ and $\mathrm{B}$ tests $\left(\sigma_{\text {compression }}>\sigma_{\text {tension }}\right)$. Consequently, it is concluded that there is no memory effect of the test onset $\left(\sigma_{\text {part2 }}>\sigma_{\text {part1 }}\right)$.

\subsection{Acoustic emission}

4.2.1. Tensile test. Previous studies [2, 10] have already reported on the deformation mechanisms activated during tensile tests performed at room temperature for two different microstructures of grade $702 \propto$ zirconium. They show that the acti- vation of $(11 \overline{2} 1)\langle 11 \overline{2} \overline{6}\rangle$ twins depends on the grain size and that it is never observed for a material with a small grain size $(15 \mu \mathrm{m})$ even though $(10 \overline{1} 2)\langle 10 \overline{1} \overline{1}\rangle$ are observed for all grain sizes (15 or $500 \mu \mathrm{m})$. For the sake of simplicity, $(10 \overline{1} 2)\langle 10 \overline{1} \overline{1}\rangle$ are called Type I and $(11 \overline{2} 1)\langle 11 \overline{2} \overline{6}\rangle$ are called Type II twins.

In Fig. 5, represents a typical plot of the amplitude $\left(V_{\mathrm{c}}\right)$ vs the efficiency value $\left(V_{\text {r.m.s. }}\right)$ of acoustic emissions for a grade $702 \alpha$ zirconium, with small grain size $(15 \mu \mathrm{m})$. Since only Type I twins are activated, the acoustic emissions recorded during the test and characterized by their shape factor $\left(\Delta V_{\mathrm{c}} / \Delta V_{\text {r.m.s. }}\right)$ (Table 3) can be associated with the activation of this mechanism and will be called "Type I". In the same figure, $\triangle$ represents the same plot for $\beta$ treated zirconium; in this case, two different types of acoustic emissions (two different shape factors) are recorded. Each signal can be associated with a unique twinning mechanism as mentioned in Table 3. Consequently, the acoustic signals associated with the $(11 \overline{2} 1)\langle 11 \overline{2} \overline{6}\rangle$ twinning system are called "Type II" in the following.

Table 3. Shape factors $\Delta V_{\mathrm{c}} / \Delta V_{\text {r.m.s. }}$ of twinning systems for tensile tests performed at room temperature

\begin{tabular}{|c|c|c|c|}
\hline & Grain size $(\mu \mathrm{m})$ & $\{10 \overline{1} 2\}\langle 10 \overline{1} \overline{1}\rangle$ & $\{11 \overline{2} 1\}\langle 11 \overline{2} \overline{6}\rangle$ \\
\hline Grade $702 \beta$ treated zirconium & 500 & $5.05( \pm 20 \%)$ & $1.07( \pm 4 \%)$ \\
\hline Grade $702 \alpha$ treated zirconium & 15 & $3.50( \pm 1 \%)$ & - \\
\hline
\end{tabular}




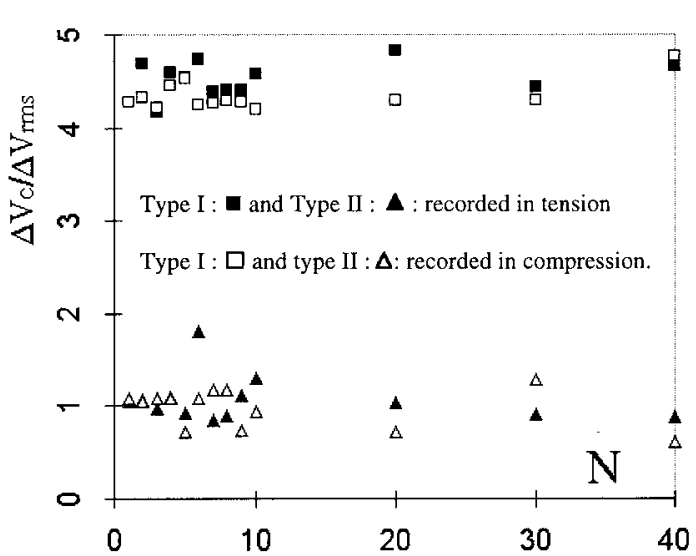

Fig. 6. Acoustic emission in fatigue: shape factors for twinning systems vs $N(\Delta \varepsilon / 2=0.80 \%)$.

4.2.2. Tension/compression fatigue tests performed on $\beta$ treated zirconium. For $\Delta \varepsilon / 2=0.80 \%$, the shape factor for each event, recorded in tension and in compression, is reported in Fig. 6 for a type B test. It shows that there are two different types of events corresponding to Type I and II emissions and occurring either in tension or in compression. Moreover, the number of events per cycle does not remain constant with the number of cycles $(N)$ (Fig. 7). First it increases during the first cycles, and then decreases continuously. Second, there are more events in tension than in compression during the first cycles, but the values are equal for larger $N$.

The critical stress for the inception of the first acoustic emission of each cycle, tends to increase with $N$ [Fig. 7(b)]. This is in agreement with Fig. 7 (a) since the number of events decreases with $N$. Finally, it can be noticed that only for the first cycle, the inception stress for the first acoustic signal in compression is lower than in tension; after that, the effect is reversed. This property is consistent with Fig. 4, where $\sigma_{\text {tension }}>\sigma_{\text {compression for the }}$ first cycle of type B test. That inception stress, equal in compression and tension, is in agreement with the fact that the number of events is the same in tension and compression after about 10 cycles, when the cycles symmetrize.

For $\Delta \varepsilon / 2<0.30 \%$, only $(10 \overline{1} 2)\langle 10 \overline{1} \overline{1}\rangle$ twins are observed in tension and in compression, and only Type I acoustic signals are recorded. This is because under these conditions, the critical stress for the inception of type II twinning is never reached [2].

4.2.3. Microscopic characterization. A type A test performed inside the SEM allows the observation of the sample surface under loading conditions (for $\sigma=260$ and $-260 \mathrm{MPa}$ ) from the first cycle to rupture (377 cycles). The corresponding total strain amplitude $\Delta \varepsilon / 2$ is approximately $1 \%$.

The deformation mechanisms are identical to those in monotonic tension [2]: $(10 \overline{1} 0)\langle 1 \overline{2} 10\rangle$ pris- matic slip, $(10 \overline{1} 2)\langle 10 \overline{1} \overline{1}\rangle$ and $(11 \overline{2} 1)\langle 11 \overline{2} \overline{6}\rangle$ twinning. Their activations depend on the colony orientation. Moreover, if a fatigue test is stopped after a certain number of complete cycles, only a few twins are observable. In contrast, if the test is stopped after half a cycle, for instance if only the tension part is completed, many twins are observed as for the tests under monotonic conditions.

Twinning is partially reversible (Fig. 8). Indeed, twins appear during part 1 of the cycle (tension), tend to disappear during part 2 (compression) and reappear during the next cycle. The consequence of such behaviour is illustrated in Fig. 9: damage is located at the twin boundaries and can be observed after only 25 cycles [Fig. 9(a)]. Its evolution leads to a crack located on the twin boundaries [Fig. 9(b)]. The undeformed microgrids, in the vicinity of the cracks, indicate that this damage mechanism remains highly localized. However, it is possible to observe some extrusions in the vicinity of the twins [Figs 9(a) and (b)].

Moreover, in the case of fatigue tests performed at $\Delta \varepsilon / 2<0.30 \%$, the fracture surface presents some areas (several hundred micrometres wide, typically the grain size) without any dimple or fatigue striation (Fig. 10). They can be qualified as "quasi-cleavage" areas; they correspond to a crack propagation along a twin boundary. This phenomenon is also observed for $\Delta \varepsilon / 2>0.50 \%$, but in this case, the contribution of twinning to the global deformation becomes less important than the contribution of slip. Prismatic slip localized along the lath boundaries is dominant, as for monotonic tensile tests. A previous study [2] has shown that this localized prismatic slip results in the localization of damage and crack propagation along the lath boundaries (Fig. 11).

\section{DISCUSSION}

\subsection{Macroscopic mechanical behaviour}

For low cycle fatigue tests performed at room temperature and in the range of $10^{-4}<\dot{\varepsilon}<10^{-3} / \mathrm{s}$, there is no isotropic hardening in large $\beta$ treated zirconium grains (Fig. 3). This is in agreement with the results obtained by Robinet [11], on small grain zircaloy-4 $(\approx 10 \mu \mathrm{m})$, which does not allow the activation of twinning mechanisms.

Therefore it can be concluded that there is no significant isotropic hardening in zirconium for all grain sizes. This result confirms what is generally assumed for prismatic glide and justifies neglecting the contribution of twinning to the macroscopic isotropic hardening.

\subsection{Microscopic mechanical behaviour}

The kinematical part is the major component of the hardening behaviour (Fig. 3) and is equivalent 

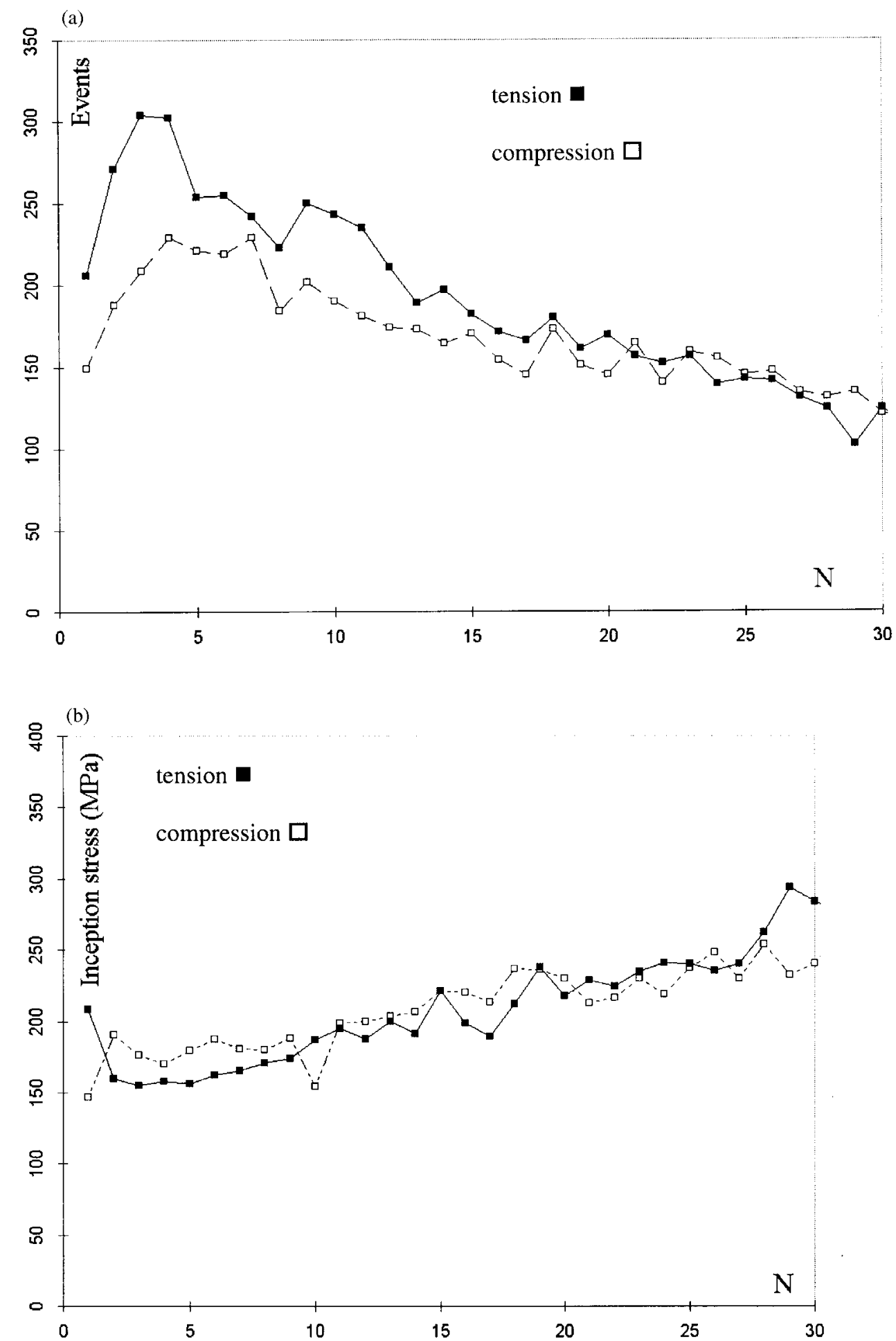

Fig. 7. Acoustic emission analysis for type B uniaxial fatigue test $(\Delta \varepsilon / 2=0.80 \%)$. (a) Number of events per cycle vs $N$. (b) Average critical stress for the inception of the first two events vs $N$.

at the microscopic scale to the internal back stress $\tau_{\mathrm{b}}$, that can be interpreted as being the origin of the Bauschinger effect often observed in zirconium and zirconium alloys $[12,13]$. Indeed, this effect is linked to the existence of long range interactions generally explained either by a "composite effect", due to the interactions between dislocation walls of high dislocation density separated by soft areas of low dislocation density [14], or by a "second phase effect" resulting from the interactions between sec- 

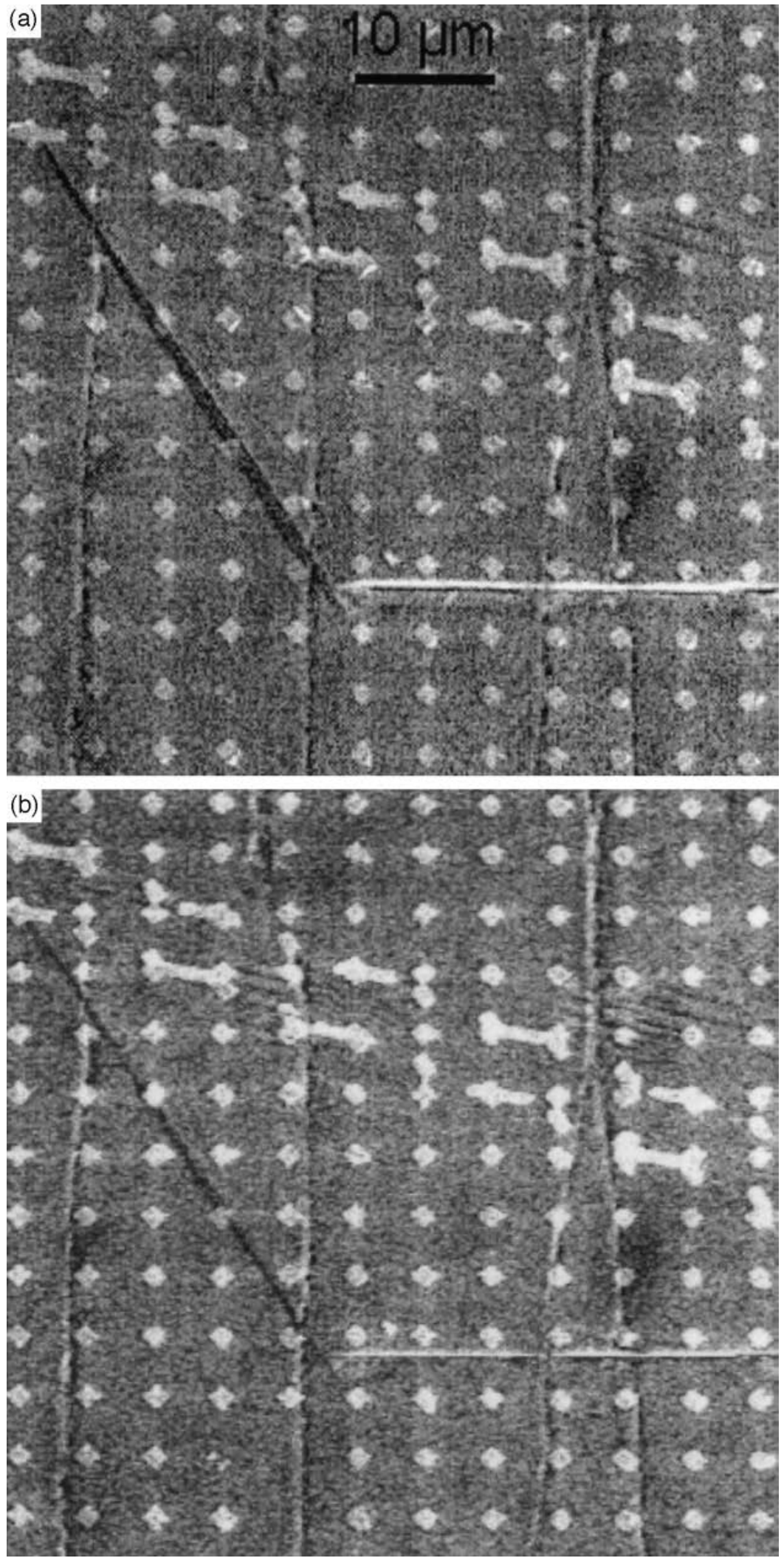

Fig. 8. The reversal of two $(11 \overline{2} 1)\langle 11 \overline{2} \overline{6}\rangle$ twins during type A fatigue test. The lath boundaries are vertical; the dots are part of a microgrid (vertical stress axis): (a) $\sigma=260 \mathrm{MPa}$, two twins have nucleated; (b) $\sigma=-260 \mathrm{MPa}$, the twin traces almost disappear. 

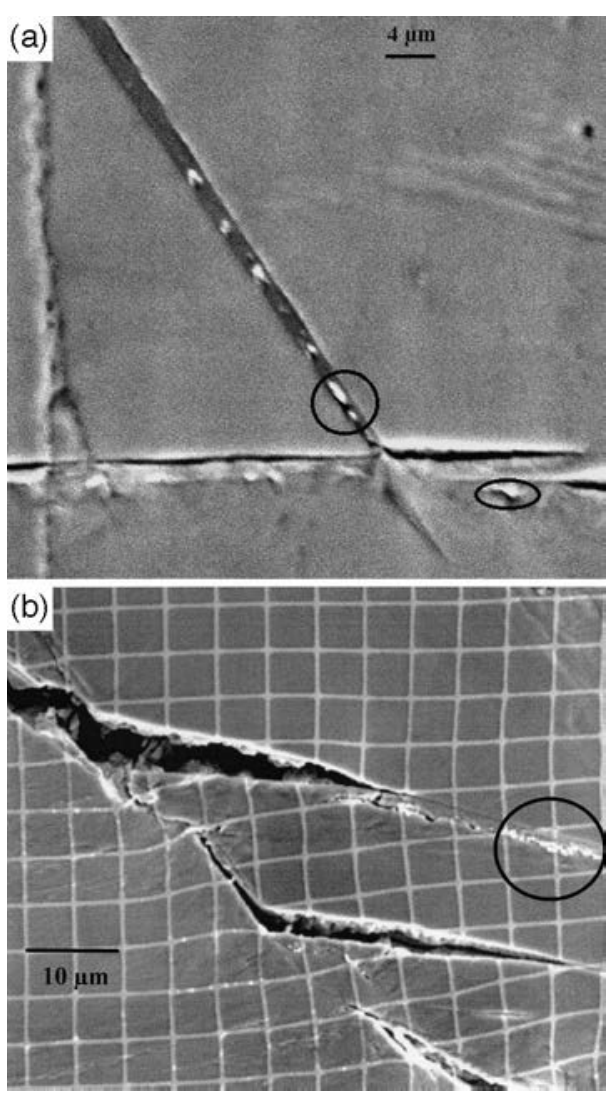

Fig. 9. Damage and extrusions. (a) Same grain as in Fig. 8: damage and extrusions located at the horizontal twin boundaries $(N=25)$. (b) Crack propagation along the damaged twin boundaries $(N=377$; broken specimen $)$.

ond phase particles and matrix. But, in the case of anisotropic materials with very few deformation systems like $\mathrm{Zr}$, another explanation can be proposed: the back stress $\tau_{\mathrm{b}}$ could be due to incompatibilities between the grains of the polycrystal as mentioned by Hutchinson [15]. $\tau_{\mathrm{b}}$ is directly proportional to the grain size and linked to the crystallographic texture (disorientation between the grains). This last assumption was already suggested by MacEwen et al. [13] in the case of zirconium alloys.

In our study, transmission electron microscopy (TEM) analysis performed on samples deformed at $\Delta \varepsilon / 2=0.80 \%$ after 700 cycles allows the conclusion that there is neither interaction between the dislocations and the precipitate networks (localized on the lath boundaries) nor occurrence of dislocation cells. Consequently, the kinematical hardening is probably due to the polycrystal effect. Furthermore, the macroscopic behaviour shows that there is no evolution of the hardening effect for cyclic loading. From this global characterization, it can also be noted (Fig. 3) that the friction stress $\tau_{\mathrm{f}}$, taken as equivalent to the critical stress for dislocation displacement, is consistent with the critical resolved shear stresses of the deformation mechanisms

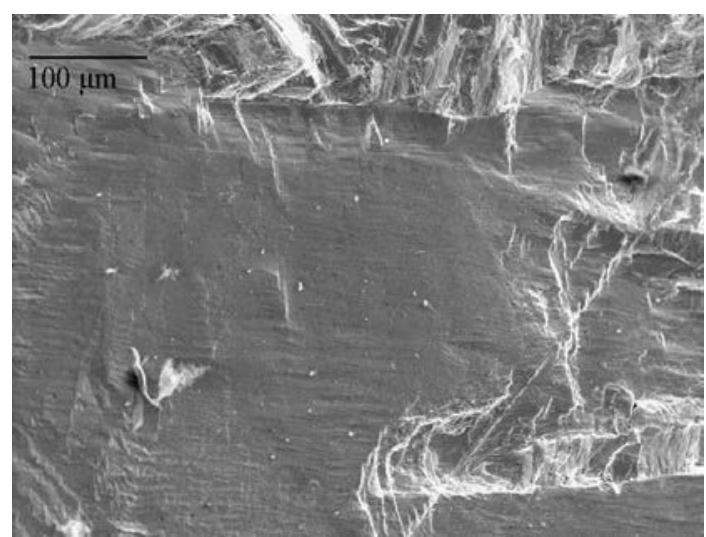

Fig. 10. A quasi-cleavage zone in the fracture surface.

( $\approx 100 \mathrm{MPa})$ already estimated in Ref. [2] at the SEM scale. This value seems to remain stable with the cycles; it implies once more that there is no significant hardening effect.

Nevertheless, even if any major intrinsic hardening mechanism is detected, it seems that at the onset of the tests, the stress response is not totally symmetric $\left(\sigma_{\text {part1 }} / \sigma_{\text {part2 } 2}\right)$ for a symmetric $\Delta \varepsilon / 2$ imposed strain. This effect disappears after a few cycles. A tentative explanation is given in the following.

\subsection{Deformation mechanisms characterization}

From Figs 5 and 6, it is clear that acoustic emission reveals the existence of $(10 \overline{1} 2)\langle 10 \overline{1} \overline{1}\rangle$ and $(11 \overline{2} 1)\langle 11 \overline{2} \overline{6}\rangle$ twinning that are both active in tension and compression. The microscopic characterization and the observation of only a few twins after symmetrical loading allow the conclusion that the emissions correspond to the appearance and disappearance of twins, but not to the activation of two different types of mechanisms (tensile twins and compression twins as those reported in Ref. [6]). Nevertheless, it is easier to activate twinning in tension than in compression (Fig. 7). Indeed, more events are detected in tension than in compression, and the critical stress for twin inception is lower in tension than in compression (except for the first cycle starting in compression-type $\mathrm{B}$ test). This conclusion does not contradict the finding that the stress ratio $\left(\sigma_{\text {part1 } 1} / \sigma_{\text {part2 }}\right)$, between the first cycle of type A and B tests (Fig. 4), is exactly the same. So, the non-symmetric response under symmetric loading can be explained by the non-symmetric behaviour of twins (Fig. 8). Indeed, twins appear in the first half-cycle and then disappear during the second half-cycle; their contribution to the macroscopic strain is less important for the reverse part of the loading so that an increment of plastic glide is needed to reach the symmetric strain amplitude. The consequence of such an increment is that $\sigma_{\text {part2 }}^{\max }>\sigma_{\text {part1 }}^{\max }$. After the first cycle, there is no differ- 


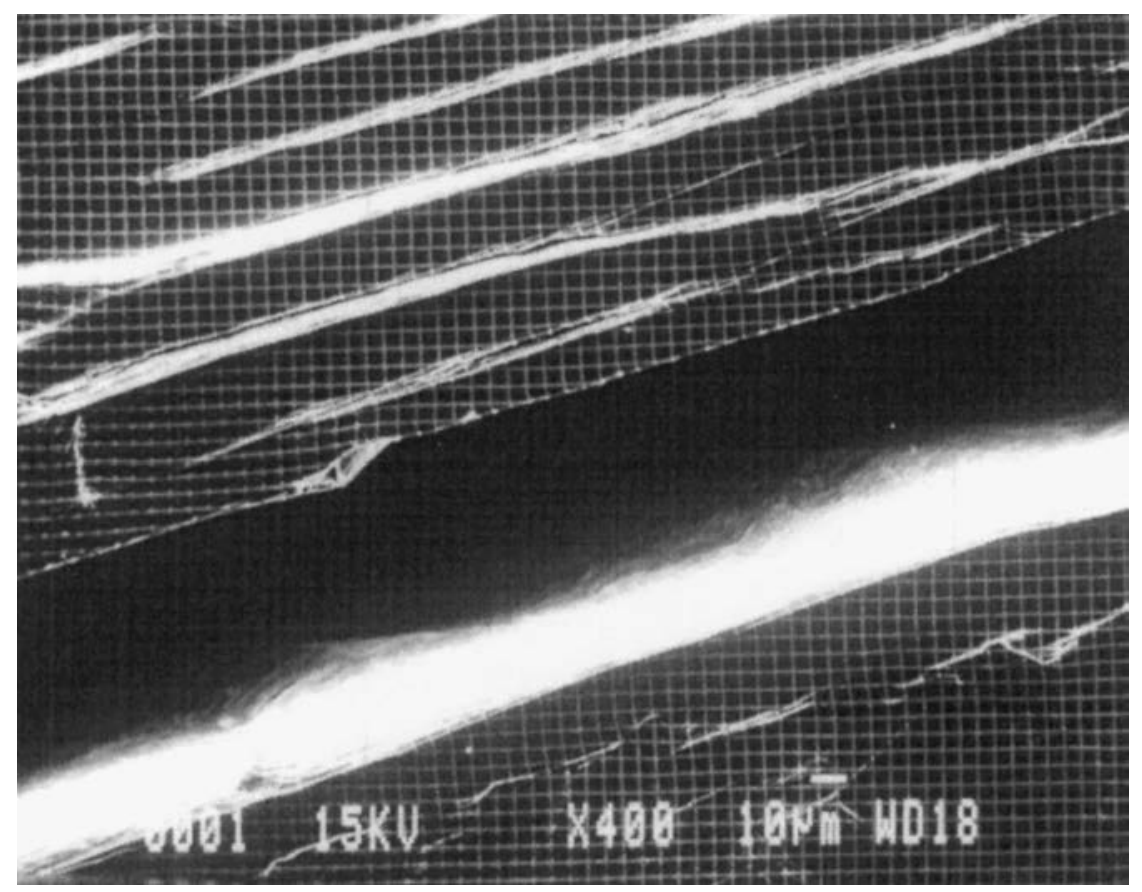

Fig. 11. Cracks propagating along localized prismatic slip bands as under monotonic tensile test [2]. $\Delta \varepsilon / 2=0.8 \%$.

ence between $\mathrm{A}$ and $\mathrm{B}$ tests. This could be explained by the greater ease in activating twinning under tension than under compression [Figs 7(a) and (b)]. So, for test B and during the tension part of the first cycle, both reversal of "partl" twins and activation of some "tension" twins occur. After this cycle, the memory of the loading direction at the test onset vanishes.

Finally, the increase in the inception stress [Fig. 7(b)] and the decrease in the number of twins [Fig. 7(a)] with $N$ mean that there is a hardening mechanism for twinning, even if the macroscopic behaviour seems to be insensitive to twinning (Fig. 3). Moreover, a preliminary study at the TEM scale reveals the occurrence of two parallel "walls" of dislocations (Fig. 12), corresponding to the location of former twin boundaries close to the $\langle 11 \overline{2} 0\rangle$ direction. This area (Fig. 12) has been observed under different diffraction conditions: $\vec{g}=1 \overline{1} 00, \vec{g}=01 \overline{1} 0$, $\vec{g}=10 \overline{1} 0$. The walls are never out of contrast; so the wall dislocations are neither $\langle a\rangle$, nor $\langle c\rangle$, nor $\langle c+a\rangle$. Song and Gray III [16-18] have already reported the existence of such dislocation structures with a new type of stacking fault observed within deformation twins in titanium and zirconium. In their studies, the stacking faults are associated with the shuffling of atoms due to twinning. In our study, more tests are required to confirm the existence of this type of dislocations and stacking faults and eventually to understand their consequences on hardening and damage mechanisms.

\subsection{Damage nucleation}

Twinning mechanisms cannot be disregarded from a damage description of the low cycle fatigue. Damage appears early on at twin boundaries (Fig. 9). This phenomenon is particularly important if the microstructure consists of very large grains $(500 \mu \mathrm{m})$ and if the strain amplitude is very small. Indeed, in that instance, the contribution of twins to deformation cannot be disregarded compared to slip. Moreover, if the material is strongly textured (rolling texture) and if the loading direction is favourable for twin activation (e.g. parallel to the transverse direction for a rolling texture), the twin contribution to damage is then increased. Finally, since twins are well known to be observed more frequently near free surfaces than in the bulk, then damage due to twins is more critical for thin structures (tubes) than for thick ones in low cycle fatigue.

\section{CONCLUSION}

The experimentation at different scales has revealed the role of twinning under fatigue conditions at room temperature. Twinning is a deformation mechanism admitting partial reversibility like slip. However, it seems that the irreversible part of twinning leads to the occurrence of damage localized along twin boundaries after only a few cycles for $\Delta \varepsilon / 2<1 \%$. The consequences of this reversibil- 


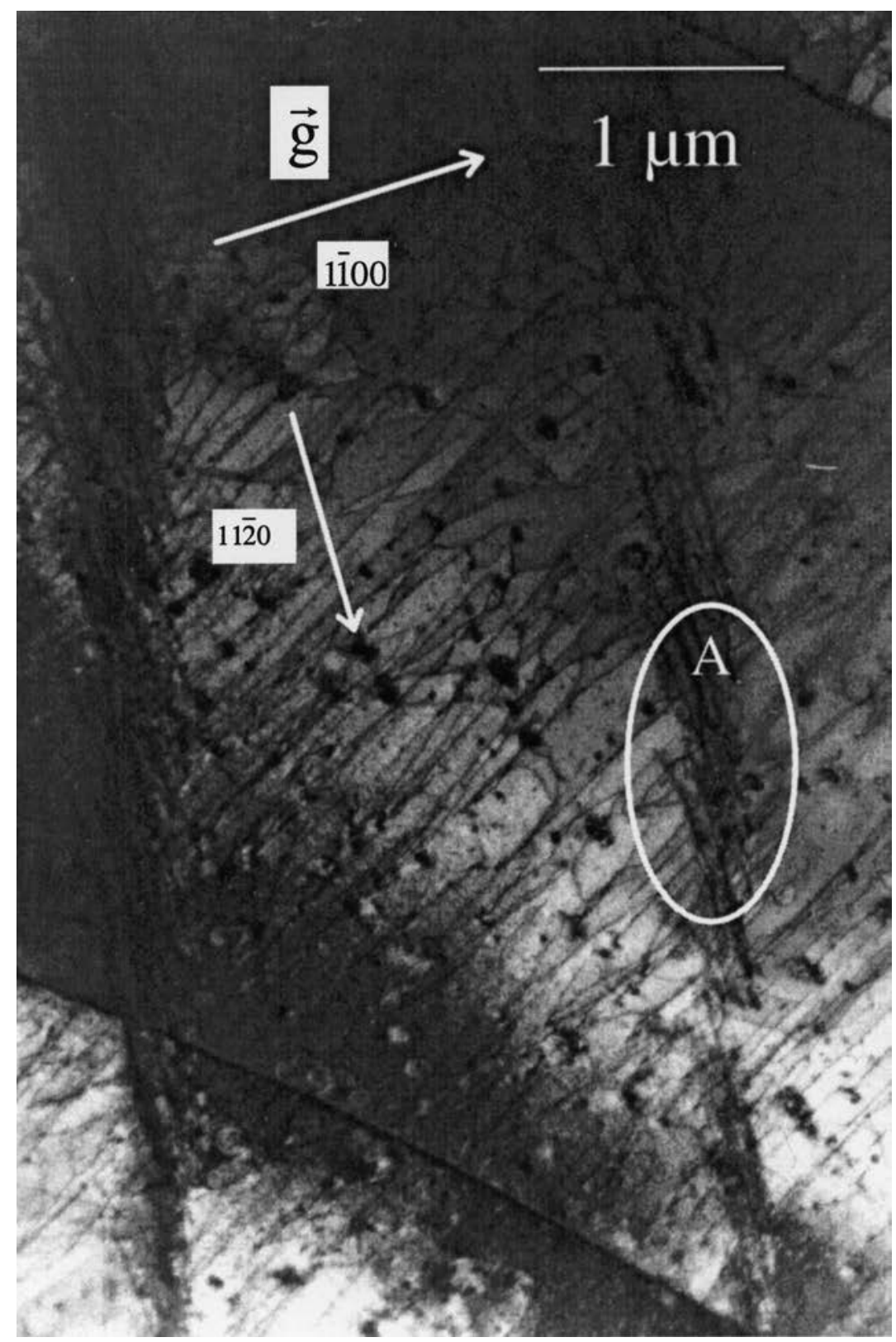

Fig. 12. TEM observation after sample fracture. Dislocation walls (A) are parallel to a twin boundary (close to $\langle 11 \overline{2} 0\rangle$ ) passing through several laths.

ity are more important for low applied stress. In this case, twinning cannot be disregarded compared to slip as for monotonic tensile tests since damage on twins induces a very detrimental "quasi-cleavage" mechanism.

Acknowledgements - The authors wish to thank the CEA/ CEREM for supplying both materials and financial support, M. Terrien (LMS) for his assistance with the acoustic emission and J. Tchir (LMS) for his contribution to the study of the macroscopic fatigue behaviour.

\section{REFERENCES}

1. Crépin, J., Bretheau, T., Caldemaison, D., Barbu, A. and Jazkierowitcz, G., J. Mater. Sci., 1997, 32, 4841.

2. Crépin, J., Bretheau, T. and Caldemaison, D., Acta metall. mater., 1995, 43, 3709.

3. Doquet, V., Caldemaison, D. and Bretheau, T., Proceedings of the Fourth International Conference on Biaxial and Multiaxial Fatigue, St Germain en Laye, Vol. II, 1994, p. 19.

4. Allais, L., Bornert, M., Bretheau, T. and Caldemaison, D., Acta metall. mater., 1994, 42, 3865.

5. Roget, J., Technique de l'ingénieur, R3200-1, 1999. 
6. Reed-Hill, R. E., in Deformation Twinning, AIME Met. Conf. Series, Vol. 25. Gordon \& Breach, New York, 1964, p. 295.

7. Cottrell, A. H., in Dislocations and Plastic Flow in Crystals. Oxford University Press, London, 1953, p. 111.

8. Kuhlmann-Wilsdorf, D. and Laird, C., Mater. Sci. Engng, 1979, 37, 111

9. Lemaitre, J. and Chaboche, J. L., Mécanique des matériaux solides, 2nd edn. Dunod, Paris, 1988.

10. Care, S., Thèse de doctorat, École Polytechnique, 1994.

11. Robinet, P., Thèse de doctorat, U.F.R. des Sciences et Techniques de l'Université de Franche-Comté, 1995.

12. Christodoulou, N., Acta metall., 1989, 37(2), 529.

13. MacEwen, S. R., Ells, C. E. and Woo, O. T., J. nucl. Mater., 1981, 101, 336.

14. Mughrabi, H., Acta metall., 1983, 31, 1367.

15. Hutchinson, J. W., J. Mech. Phys. Solids, 1964, 12, 11.

16. Song, S. G. and Gray III, G. T., Acta metall. mater., 1995, 43(6), 2325.

17. Song, S. G. and Gray III, G. T., Acta metall mater., 1995, 43(6), 2339.

18. Song, S. G. and Gray III, G. T., Phil. Mag. A, 1995, 71(2), 263. 